\title{
Outcomes of Rhegmatogenous Retinal Detachment
}

\author{
Muhammad Tariq Khan ${ }^{1}$, Sidrah Riaz ${ }^{2}$, Khurram Azam Mirza ${ }^{3}$ \\ ${ }^{1-2}$ Akhtar Saeed Medical \& Dental College, Lahore, ${ }^{3}$ Hameed Latif Medical Centre, Lahore,
}

\begin{abstract}
Purpose: To study demographic characteristics and treatment outcomes of Rhegmatogenous retinal detachment in a private Vitreo-retinal setup of Lahore.

Study Design: Cross sectional Observational study.

Place and Duration of Study: Lahore Medicare Eye Center, from March 2017 to April 2019.

Methods: Total 102 patients with Rhegmatogenous retinal detachment (RRD) were included. Patients with retinal detachment other than RRD were excluded. Detailed history and ocular examination was performed. Type of break, procedure adopted for RRD repair and type of endo-tamponade were also recorded. These patients had either 23 G pars plana vitrectomy (PPV) or scleral buckling (SB) procedures or combined scleral buckling with PPV. Patients were followed-up for six months.

Results: Out of 102 total RRD cases, $63.70 \%$ were males and $36.30 \%$ were females. Mean age was $47.44 \pm$ 18.44 years. Macula was attached in $48 \%$ and off in $52 \%$. Phakic patients were $53.92 \%$, pseudophakic $41.19 \%$ and aphakic $4.90 \%$. Position of break in RRD was superotemporal in $39.2 \%$, inferotemporal in $30.4 \%$ and inferonasal in $2.9 \%$. Total RRD was observed in $27.5 \%$ patients. One or more breaks were identified in $82.4 \%$ patients and giant tear in $4.9 \%$. Three ports $23 \mathrm{G} \mathrm{PPV}$ was done in $64.7 \%$, PPV with IOL in $18.6 \%$, scleral buckling in $10.8 \%$ and combined PPV + SB in 5.9\% patients. Anatomical success was achieved in $96.07 \%$ patients on first attempt while 3.9\% needed second surgery within six months of follow-up.
\end{abstract}

Conclusion: Anatomical success rate in retinal attachment surgeries in experienced hands is comparable with leading international retinal centers of the world.

Key Words: Rhegmatogenous retinal detachment, Pars plana vitrectomy, Scleral buckling, Silicon oil.

How to Cite this Article: Khan MT, Riaz S, Mirza KA. Outcomes of Rhegmatogenous Retinal Detachment. Pak J Ophthalmol. 2021, 37 (1): 115-119.

Doi: https://doi.org/10.36351/pjo.v37i1.1073

\section{INTRODUCTION}

Retinal detachment includes rhegmatogenous, tractional and exudative types. ${ }^{1,2}$ RRD is the commonest type of retinal detachment with worldwide incidence of 6.3 to 17.9 per 100,000 populations. ${ }^{3}$ Vitreous is a unique structure, composed of water, collagen fibers and hyaluronic acid which plays a

Correspondence: Sidrah Riaz

Akhtar Saeed Medical \& Dental College, Lahore

Email:sidrah893@yahoo.com

Received: 2021

Accepted: 2021 pivotal role in the development of RRD. The giant retinal tear (GRT) is defined as full thickness retinal break in neurosensory retina with circumferential extent of at least 3 clock hours in the presence of posterior vitreous detachment (PVD). ${ }^{4}$ RRD can result in total vision loss if not treated timely and properly. There are many approaches for treatment of retinal detachment like scleral buckling (SB), pars plana vitrectomy (PPV), combined SB and PPV and pneumatic retinopexy.

History of scleral buckling dates back to $1950^{5}$ and PPV was introduced in 1971 by Robert Machemer ${ }^{6}$, who used disposable 17-gauge cutter. Recently 20G, $23 \mathrm{G}, 25 \mathrm{G}$ and $27 \mathrm{G}$ PPV is being used by different eye 
surgeons in different centers. ${ }^{7}$ These three techniques are used interchangeably depending upon the surgeon's skills, training, type of retinal detachment, age of patient, lens status, ocular media clarity and vitreous status. The traditional SB procedure is performed usually in young phakic patients and PPV in pseudophakic patients with PVD and complicated RRD. SB has advantage of early visual rehabilitation and prevention of cataract formation whereas PPV has benefit of less pain and management of large, posterior breaks under L/A.

In international literature the surgical success rate of retinal surgery in terms of achieving retinal attachment for RRD is variable. For SB, it is $74-94 \%$ and for PPV, it is $75-96 \%$. $^{8,9}$ The commonly used agents for internal tamponade are silicon oil, expansile gases, perfluorocarbon liquid (PFCL) and semiflourinated alkanes. $^{10}$ The choice of internal tamponading agent is a debatable issue but silicon oil is commonly used in retinal surgeries since 1962 when Cibis used it for the first time in management of RD.

Purpose of this study was to find out the demographic characteristics and anatomical results of RRD in a private set up in Lahore, Pakistan.

\section{METHODS}

After approval from Ethical review board, patients were recruited by convenient sampling technique. Over the two years period from March 2017 to April 2019, all patients with Rhegmatogenous retinal detachment (RRD) presenting to private vitreoretinal surgeon were included in the study. All surgeries were performed at Lahore Medicare Eye Center, Lahore. The diagnosis was clinical and B scan was done if required. Other causes of retinal detachments like tractional retinal detachment (TRD), combined RRD and TRD, exudative retinal detachments and funnelshaped RD were excluded. Total 102 eyes were included in this study. Surgeries were performed under local or general anesthesia depending upon patient's age, procedure and patient's health. All cases were done by a single senior retinal surgeon. Detailed history and ocular examination were performed. Patients were also enquired about associated factors like history of trauma and refractive error. Patient's age, gender, laterality of eye, lens status, macular status, position and type of break, procedure adopted for RRD repair and type of endo-tamponade were noted.
SB was performed under general anesthesia (GA). After $360^{\circ}$ peritomy, $3.5 \mathrm{~mm}$ silicon band was anchored with 5/0 ethibond. SRF drainage and cryotherapy was done with indirect ophthalmoscope. Peritomy was closed with 6/0 vicryl. 23-G PPV was performed under local anesthesia (LA) or GA, with 3ports using BIOM viewing system. Vitrectomy was completed after staining with triamcinolone and indentation for peripheral shaving. Retinotomy was done at suitable site to drain SRF. Air fluid exchange, endolaser, injection of suitable tamponading agent and digital checking of IOP were done before port closure. Patients were advised antibiotic eye drops, oral medicines and postoperative positioning. Follow-up was done on the first day, one week and one month postoperatively. These patients were followed-up for six months. On each visit, vision, retinal status and intraocular pressures were checked. Data was analyzed using SPSS 25.

\section{RESULTS}

There were 102 RRD cases, 93 primary RD (65 males, 37 females) and 9 with re-detachment after failed primary surgery (done somewhere else and referred for second surgery). Mean age was $47.44 \pm 18.44$ years (Fig 1). For further details, see table 1 and 2.

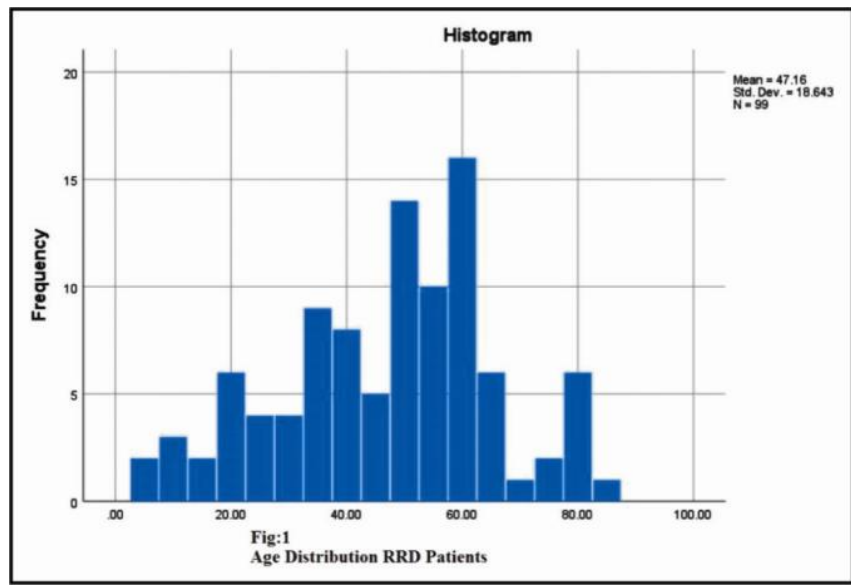

Fig. 1: Age Distribution in RRD Patients.

Table 1: General Characteristics.

\begin{tabular}{lcc}
\hline Gender & & \\
\hline Male & 65 & $63.70 \%$ \\
Female & 37 & $36.30 \%$ \\
Macula & & \\
Macula Off & 49 & $48.00 \%$ \\
Macula On & 53 & $52.00 \%$
\end{tabular}




\begin{tabular}{|c|c|c|}
\hline \multicolumn{3}{|l|}{ Lens } \\
\hline Pseudophakia & 42 & $41.18 \%$ \\
\hline Phakia & 55 & $53.92 \%$ \\
\hline Aphakia & 5 & $4.90 \%$ \\
\hline \multicolumn{3}{|l|}{ RD Position } \\
\hline Superotemporal & 40 & $39.20 \%$ \\
\hline Inferotemporal & 31 & $30.40 \%$ \\
\hline Superonasal & 0 & $0.00 \%$ \\
\hline Inferonasal & 3 & $2.90 \%$ \\
\hline Total RD & 28 & $27.50 \%$ \\
\hline \multicolumn{3}{|l|}{ Eye } \\
\hline Right & 49 & $48.00 \%$ \\
\hline Left & 53 & $52.00 \%$ \\
\hline \multicolumn{3}{|l|}{ Anesthesia } \\
\hline LA & 80 & $78.40 \%$ \\
\hline GA & 22 & $21.60 \%$ \\
\hline \multicolumn{3}{|l|}{ Break } \\
\hline No Break & 13 & $12.70 \%$ \\
\hline One or More & 84 & $82.40 \%$ \\
\hline Giant Tear & 5 & $4.90 \%$ \\
\hline \multicolumn{3}{|l|}{ Tamponade } \\
\hline Silicon Oil 1000 & 50 & $49 \%$ \\
\hline Silicon Oil 5000 & 34 & $33.33 \%$ \\
\hline Gas & 7 & $6.90 \%$ \\
\hline \multicolumn{3}{|l|}{ Procedure } \\
\hline PPV & 66 & $64.70 \%$ \\
\hline $\mathrm{PPV}+\mathrm{IOL}$ & 19 & $18.60 \%$ \\
\hline SB & 11 & $10.80 \%$ \\
\hline Combined & 6 & $5.90 \%$ \\
\hline
\end{tabular}

Table 2: Procedure \& Lens Status.

\begin{tabular}{lccc}
\hline Procedure & Phakic & Pseudo Phakia & Aphakia \\
\hline PPV & 22 & 41 & 3 \\
PPV + IOL & 19 & 0 & 0 \\
SB & 10 & 1 & 0 \\
Combined & 4 & 0 & 2 \\
\hline
\end{tabular}

\section{DISCUSSION}

The visual loss due to Rhegmatogenous retinal detachment remains a major concern for vitreoretinal surgeons as RD affects 0.6 to 1.8 people/100000/ year. ${ }^{11}$ In this study, maximum number of patients were between 50 and 60 years. Studies from United States and European countries have shown similar single peaked age distribution but data from East Asia and Scotland, on the contrary, had showed bi modal age distribution in patients of RRD. First peak in age group $20-30$ years and $2^{\text {nd }}$ in $60-70$ years. ${ }^{12-14}$ It may be associated with increased prevalence of myopic refractive error in young population.

Mean age of patients with RRD in our study for phakic patients was 41.22 years and 56.19 years for pseudophakic patients. The younger patients were more in SB and combined PPV+SB group. Pseudophakia was an important factor associated with development of RRD. The literature review has revealed that pseudophakic patients with RRD were in their $6^{\text {th }}$ decade at the time of presentation. ${ }^{15}$ Large scale studies have consistently confirmed that frequency of RRD was more in men than women. ${ }^{16-18}$ Our data showed male to female ratio of $2: 1$. The reason for male predominance in RRD patients is not clear. As more men are bread-earning members of their family in Asian families so they are more prone to external environment and blunt trauma.

An interesting finding was identification of more temporal retinal breaks 71 (69.60\%), which may be related to early presentation as patients become symptomatic early due to involvement of central vision. One or more than one breaks were identifiable in $89(87.30 \%)$ and no break was found in 13 (12.70\%). Myopia was a common association of RRD in younger age group, observed in $13(28.26 \%)$ cases. Vitreous degeneration and liquefaction with increasing age, myopia and cataract surgery, resulting in PVD, is an important factor in pathogenesis of RRD. ${ }^{19,20}$

Pars plana vitrectomy (PPV) with or without IOL implantation is a common procedure adopted worldwide for RD repair. Pars plana vitrectomy showed better outcome as compared to SB in pseudophakic RRD. ${ }^{21,22}$ Pseudophakia was poor prognostic factor in management of RRD using SB but not with PPV. ${ }^{21}$ Pars plana vitrectomy is also indicated in complicated RRD with proliferative vitreoretinopathy (PVR). Recent advancement in technology had made vitrectomy more common procedure in management of phakic RRD. ${ }^{23}$ Majority of ophthalmic surgeons are of the opinion that PPV alone without SB is enough for successful repair of RRD. ${ }^{24}$ Better vitrectomy instruments and wide angle viewing system may be the reason for dramatic increase in PPV procedures. Advantage of SB over PPV include prevention of cataract progression, early visual rehabilitation and no specific head position restriction after surgery. Repeated taking on and off the indirect ophthalmoscope, deeper anesthesia, and myopic shift induction postoperatively are relatively undesirable effects.

Complications associated with silicon oil are raised IOP, cataract formation and emulsification which were managed medically or surgically by same principal surgeon. Successful surgical repair was achieved in majority of cases after single surgery, only $4 \%$ required $2^{\text {nd }}$ operation. 
The limitations of study are retrospective nature of study, small sample size and private sector patients so financial matter can create bias. There is a need of multicentric studies on larger number of patients.

\section{CONCLUSION}

Anatomical success rates in retinal attachment surgeries in experienced hands are comparable with leading international retinal centers of the world.

\section{Ethical Approval}

The study was approved by the Institutional review board/ Ethical review board. (ET/02/17)

\section{Conflict of Interest}

Authors declared no conflict of interest.

\section{REFERENCES}

1. Park SJ, Choi NK, Choi NK, Park KH, Woo SJ. Five year nationwide incidence of rhegmatogenous retinal detachment requiring surgery in Korea. PLoS One, 2013; 8 (11): e80174.

2. Mitry D, Fleck BW, Wright AF, Campbell H, Charteris DG. Pathogenesis of rhegmatogenous retinal detachment: predisposing anatomy and cell biology. Retina. 2010; 30 (10): 1561-1572.

3. Jamil H, Farooq N, Khan MT, Jamil AZ. Characteristics and Pattern of rhegmatogenous retinal detachment in Pakistan. J Coll Physician Surg Pak. 2012; 22: 501-504.

4. Shunmugam M, Ang GS, Lois N. Giant retinal tears. Surv Ophthalmol. 2014; 59 (2): 192-216.

5. Awan A. Primary Rhegmatogenous Retinal Detachment surgery in modern Era. Pak J Ophthalmol. 2018; 34 (2). Doi. /10.36351/pjo.v 34 i 2.223.

6. Machemer R, Buettner H, Norton EW, Parel JM. Vitrectomy: a pars plana approach. Trans Am Acad Ophthalmol Otolaryngol. 1971; 75 (4): 813-820.

7. Grosso A, Arias L, Mariotti C, Faraldi F, Panico C, Figueroa M. Recent Advancements in Vitreoretinal Techniques - A Critical Reappraisal. Eur Ophth Rev. 2014; 8 (1): 46-52. Doi: 10.17925/EOR.2014.08.01.46

8. Park SW, Kwon HJ, Kim HY, Byon IS, Lee JE, Oum BS. Comparison of scleral buckling and vitrectomy using wide angle viewing system for rhegmatogenous retinal detachment in patients older than 35 years. BMC Ophthalmol. 2015; 115: 121.

9. Kobashi H, Takano M, Yanagita T, Shiratani T, Wang G, Hoshi K, et al. Scleral buckling and pars plana vitrectomy for rhegmatogenous retinal detachment: an analysis of 542 eyes. Curr Eye Res. 2014; 39 (2): 204-211.
10. Vaziri K, Schwartz SG, Kishor Ks, Flynn HW jr. Tamponade in surgical management of retinal detachment. Clin Ophthalmol. 2016; 10: 471-476.

11. Mitry D, Charteries DG, Fleck BW, Campbell H, Singh, J. The epidemiology of rhegmatogenous retinal detachment: geographical variation and clinical associations. Br J Ophthalmol. 2010; 94 (6): 678-684. Doi:10.1136/bjo.2009.157727

12. Park SJ, Choi NK, Park KH, Woo SJ. Five year nationwide incidence of Rhegmatogenous Retinal detachment requiring surgery in Korea. PLOS One, 2013; 8 (12): e80174.

13. Mitry D, Chalmers J, Anderson K, Williams L, Fleck BW. Temporal trends in retinal detachment incidence in Scotland between 1987 and 2006. Br J Ophthalmol. 2011; 95: 365-369.

14. Mitry D, Singh J, Yorston D, Siddiqui MA, Wright A. The predisposing pathology and clinical characteristics in the Scottish retinal detachment study. Ophthalmology, 2011; 118: 1429-1434.

15. Heimann H, Bartz-Schmidt KU, Bornfeld N, Weiss C, Hilgers RD, Foerster MH. Scleral Buckling versus Primary Vitrectomy in Rhegmatogenous Retinal Detachment Study Group Scleral buckling versus primary vitrectomy in rhegmatogenous retinal detachment: a prospective randomized multicenter clinical study. Ophthalmology, 2007; 114 (12): 21422154.

16. Wong TY, Tielsch JM, Schein OD. Racial difference in the incidence of retinal detachment in Singapore. Arch Ophthalmol. 1999; 117: 379-383.

17. Polkinghorne PJ, Craig JP. Northern New Zealand Rhegmatogenous Retinal Detachment Study: epidemiology and risk factors. Clin Experiment Ophthalmol. 2004; 32: 159-163.

18. Limeira-Soares PH, Lira RP, Arieta CE, Kara-Jose N. Demand incidence of retinal detachment in Brazil. Eye (Lond). 2007; 21: 348-352.

19. Elige C, Christophe M, John C, Bruno M, Francos D. PPV and SB for patients with Retinal Detachment. Ophthalmology, 2018; 9 (6): 425-429.

20. Degirmenci C, Afrashi F, Mentes J, Oztas Z, Nalcaci S, Akkin C. Evaluation of posterior vitreous detachment after uneventful phacoemulsification surgery by optical coherence tomography and ultrasonography. Clin Exp Optom. 2017; 100 (1): 4953.

21. Hocaoglu M, Karacorlu M, Ersoz MG, Muslubas IS, Arf. Vitrectomy with silicon oil tamponade for retinal detachment associated with giant retinal tear: favorable outcomes without scleral buckling. Acta Ophthalmol. 2019; 97: 271-276.

22. Arya AV, Emerson JW, Engelbert M, Hagedorn CL, Adelman RA. Surgical management of pseudophakic retinal detachments: a meta-analysis. Ophthalmology, 2006; 113 (10): 1724-1733. 
23. Park SJ, Cho SC, Choi NK, Park KH, Woo SJ. Age, sex, and time-specific trends in surgical approaches for rhegmatogenous retinal detachment: a nationwide, population-based study using the National Claim Registry. Retina, 2017; 37 (12): 2326-2333.

24. Wong CW, Wong WL, Yeo IY, Loh BK, Wong EY, Wong DW, et al. Trends and factors related to outcomes for primary Rhegmatogenous retinal detachment surgery in a large Asian tertiary eye centre. Retina, 2014; 34 (4): 684-692.

\section{Authors' Designation and Contribution}

Muhammad Tariq Khan; Professor: Concepts, Literature research, Manuscript editing, Manuscript review.

Sidrah Riaz; Assistant Professor: Design, Literature research, Data Acquisition, Data Analysis, Statistical Analysis, Manuscript preparation, Manuscript editing.

Khurram Azam Mirza; Consultant Ophthalmologist: Literature research, Manuscript editing, Manuscript review.

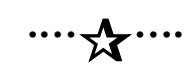

